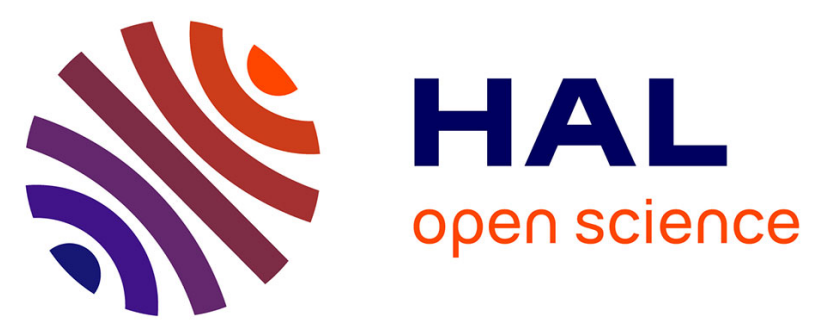

\title{
Identification of the first fumonisin mycotoxins with three acyl groups by ESI-ITMS and ESI-TOFMS following RP-HPLC separation: palmitoyl, linoleoyl and oleoyl EFB1 fumonisin isomers from a solid culture of Fusarium verticillioides
}

Tibor Bartok, Laszlo Tolgyesi, Akos Mesterhazy, Mihaly Bartok, Arpad Szecsi

\section{To cite this version:}

Tibor Bartok, Laszlo Tolgyesi, Akos Mesterhazy, Mihaly Bartok, Arpad Szecsi. Identification of the first fumonisin mycotoxins with three acyl groups by ESI-ITMS and ESI-TOFMS following RP-HPLC separation: palmitoyl, linoleoyl and oleoyl EFB1 fumonisin isomers from a solid culture of Fusarium verticillioides. Food Additives and Contaminants, 2010, 27 (12), pp.1714-1723. 10.1080/19440049.2010.521958 . hal-00643848

\author{
HAL Id: hal-00643848 \\ https://hal.science/hal-00643848
}

Submitted on 23 Nov 2011

HAL is a multi-disciplinary open access archive for the deposit and dissemination of scientific research documents, whether they are published or not. The documents may come from teaching and research institutions in France or abroad, or from public or private research centers.
L'archive ouverte pluridisciplinaire HAL, est destinée au dépôt et à la diffusion de documents scientifiques de niveau recherche, publiés ou non, émanant des établissements d'enseignement et de recherche français ou étrangers, des laboratoires publics ou privés. 


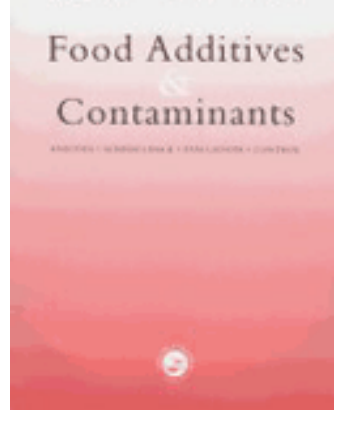

Identification of the first fumonisin mycotoxins with three acyl groups by ESI-ITMS and ESI-TOFMS following RP-HPLC separation: palmitoyl, linoleoyl and oleoyl EFB $_{1}$ fumonisin isomers from a solid culture of Fusarium verticillioides

\begin{tabular}{|r|l|}
\hline Journal: & Food Additives and Contaminants \\
\hline Manuscript ID: & TFAC-2010-226.R1 \\
\hline Manuscript Type: & Original Research Paper \\
\hline Author: & 01-Sep-2010 \\
\hline Complete List of Authors: & $\begin{array}{l}\text { Bartok, Tibor; Fumizol Ltd. } \\
\text { Tolgyesi, Laszlo; Kromat Ltd. } \\
\text { Mesterhazy, Akos; Cereal Research Co., Div. for Biotech. and } \\
\text { Resistance } \\
\text { Bartok, Mihaly; Stereochemistry Research Group of the Hungarian } \\
\text { Academy of Sciences } \\
\text { Szecsi, Arpad; Plant Protection Institute of the Hungarian Academy } \\
\text { of Sciences }\end{array}$ \\
\hline Methods/Techniques: & Chromatography - LC/MS, Extraction \\
\hline Additives/Contaminants: & Fumonisins \\
\hline Food Types: & Cereals and grain \\
\hline & \\
\hline
\end{tabular}

\section{SCHOLARONE \\ Manuscripts}




\section{Identification of the first fumonisin mycotoxins with three acyl groups by ESI-ITMS and ESI-TOFMS following RP-HPLC separation: palmitoyl, linoleoyl and oleoyl $\mathrm{EFB}_{1}$ fumonisin isomers from a solid culture of Fusarium verticillioides}

Tibor Bartók ${ }^{1,2 *}$, László Tölgyesi ${ }^{3,4}$, Ákos Mesterházy ${ }^{5}$, Mihály Bartók ${ }^{6}$ and Árpád Szécsi $^{7}$

${ }^{1}$ Faculty of Engineering, University of Szeged, Moszkvai krt. 5/7, H-6724 Szeged, Hungary

${ }^{2}$ Fumizol Ltd., Moszkvai krt. 5/7, H-6724 Szeged, Hungary

${ }^{3}$ Eötvös Loránd University Joint Research and Training Laboratory on Separation Techniques, Pázmány Péter sétány 1/A., H-1117 Budapest, Hungary

${ }^{4}$ Kromat Ltd., Péterhegyi út 98., H-1112 Budapest, Hungary

${ }^{5}$ Cereal Research Non-Profit Ltd., Alsókikötö sor 9., H-6726 Szeged, Hungary

${ }^{6}$ Stereochemistry Research Group of the Hungarian Academy of Sciences, Dóm tér 8., H-6720

Szeged, Hungary

${ }^{7}$ Department of Plant Pathology, Plant Protection Institute of the Hungarian Academy of Sciences, Herman Ottó út 15., H-1022 Budapest, Hungary

*Correspondence to: T. Bartók, Fumizol Ltd., Moszkvai krt. 5/7, H-6724 Szeged, Hungary. Email: tibor.bartok@fumizol.hu; Tel: 36-20-4264192; FAX: 36-62-544200

Running head: New fumonisins with three acyl groups

Keywords: Fusarium, mycotoxin, fumonisin isomers, EFB1, ITMS, TOFMS 


\begin{abstract}
The aim of this study was to apply RP-HPLC/ESI-ITMS and RP-HPLC/ESI-TOFMS to investigate and characterize six new higher molecular weight fumonisins (three pairs of isomers) extracted from a Fusarium verticillioides-infected solid rice culture. The ITMS and ITMS $^{2}$ spectra clearly indicated the $\mathrm{m} / \mathrm{z}$ values $(960,984$ and 986) of the protonated molecules and the $\mathrm{FB}_{1}$ toxin-like structures of these compounds, respectively. Moreover, the data evaluation software of the TOFMS equipment unambiguously demonstrated the exact masses of the protonated molecules and the suggested empirical formulae $\left(\mathrm{C}_{50} \mathrm{H}_{89} \mathrm{NO}_{16}, \mathrm{C}_{52} \mathrm{H}_{89} \mathrm{NO}_{16}\right.$ and $\left.\mathrm{C}_{52} \mathrm{H}_{91} \mathrm{NO}_{16}\right)$ of the new fumonisins, with mass accuracy in the range between 0.1 and $-1.1 \mathrm{ppm}$. Subtraction of the empirical formula of $\mathrm{FB}_{1}$ toxin $\left(\mathrm{C}_{34} \mathrm{H}_{59} \mathrm{NO}_{15}\right)$ from these formulae and correction for the mass of water split-off from the fumonisin molecule during ester formation resulted in the empirical formulae of the fumonisin backbone esterifying agents (fatty acids): $\mathrm{C}_{16} \mathrm{H}_{32} \mathrm{O}_{2}$ (palmitic acid, PA), $\mathrm{C}_{18} \mathrm{H}_{32} \mathrm{O}_{2}$ (linoleic acid, LA) and $\mathrm{C}_{18} \mathrm{H}_{34} \mathrm{O}_{2}$ (oleic acid, OA). We denoted the new compounds as esterified $\mathrm{FB}_{1}\left(\mathrm{EFB}_{1}\right)$ toxins, with the suggested names EFB 1 PA, iso$\mathrm{EFB}_{1} \mathrm{PA}, \mathrm{EFB}_{1} \mathrm{LA}$, iso-EFB $\mathrm{EA}_{1} \mathrm{EFB}_{1} \mathrm{OA}$ and iso-EFB $\mathrm{E}_{1} \mathrm{OA}$. The total amount of these new compounds comprised $0.1 \%$ of the $\mathrm{FB}_{1}$ concentration, which may be rated as significant when it is considered that these new components are significantly more apolar than earlier-described fumonisins, and their uptake into and toxicity elicited in the various tissues of living organisms may therefore also be significantly different from those of other fumonisins.
\end{abstract}

\title{
INTRODUCTION
}

Fumonisins are structurally related toxic secondary metabolites of fungi, produced primarily by Fusarium species (Rheeder et al. 2002), especially $F$. verticillioides and $F$. 
proliferatum (Seifert et al. 2003), which are worldwide pathogens of maize (Shephard et al. 1996). However, in recent papers the production of some fumonisin B (FB) analogues by Aspergillus niger has also been reported (Frisvad et al. 2007; Noonim et al. 2009; Logrieco et al. 2009; Mogensen et al. 2010). Fumonisins can cause severe diseases in animals, e.g. leucoencephalomalacia in horses (Kellerman et al. 1990) and pulmonary oedema and hydrothorax in pigs (Colvin et al. 1992; Fazekas et al. 1998; ZomborszkyKovács et al. 2002), and they can produce toxic effects in chickens (Ledoux et al. 1992) and turkeys (Weibking et al. 1993). Important data have also been published on the nephrotoxicity (Riley et al. 1994), hepatotoxicity and hepatocarcinogenicity (Gelderblom et al. 1991) of $\mathrm{FB}_{1}$ toxin in laboratory experimental rodents. Although not yet conclusively proved, the consumption of fumonisin-contaminated maize and maize-based foods (at levels of 1-10 mg kg${ }^{-1}$ ) has been linked with the promotion of human primary liver cancer (Ueno et al. 1997) and statistically with human oesophageal cancer in rural areas in different countries (Rheeder et al. 1992; Yoshizawa et al. 1994; Doko et al. 1995; Shephard et al. 2000). Fumonisins are regarded by the International Agency for Research on Cancer (IARC) as group 2B carcinogens to humans (IARC 2002).

Fumonisins are characterized by a 19-20 carbon atom long amino-polyhydroxyalkyl chain, which is generally diesterified at the hydroxy groups on C-14 and C-15 with a terminal carboxyl group of propane-1,2,3-tricarboxylic acid (tricarballylic acid, TCA) (Rheeder et al. 2002), but in some minor fumonisins the esterification involves other organic acids, such as cis-aconitic acid, oxalsuccinic acid and oxalfumaric acid (Bartók et al. 2006, 2008). Partially hydrolysed (e.g. $\mathrm{PHFB}_{1}$ ) and fully hydrolysed fumonisins (e.g. $\mathrm{HFB}_{1}$ ) have also been described (Rheeder et al. 2002; Bartók et al. 2006, 2008). In partially hydrolysed fumonisins, the backbone is monoesterified, while in fully hydrolysed compounds (usually formed during nixtamalization of maize, baking and 
frying of food products or by alkaline hydrolysis in the laboratory) there is no esterifying agent on the backbone. Depending on their chemical structures, the fumonisins can be classified into four main groups (FA, FB, FC and FP); the toxicologically most important ones being the FB analogues (Rheeder et al. 2002), primarily because the FB analogues, and especially $\mathrm{FB}_{1}$ toxin (Fig. 1), can be found in the highest concentration in maize and maize-based food- and feedstuffs (Stack 1998), and the free primary amine group on C-2 contributes significantly to the toxicity of the FB analogues (Bolger et al. 2001; Lemke et al. 2001). The first fumonisins isolated and identified in 1988 , were $\mathrm{FB}_{1}$ and $\mathrm{FB}_{2}$ toxin (Bezuidenhout et al. 1988). The amine group in the FA analogues is acetylated. The structure of the FC analogues is similar to that of the FB analogues, without the $\mathrm{C}-1$ methyl group. The most recently described group of fumonisins comprises the FP analogues, in which a 3-hydroxypyridine moiety can be found on C-2 (Musser et al. 1996).

HPLC/ESI-MS and MS/MS techniques with different types and different combinations of mass analysers have become popular in fumonisin analysis. The most significant advantages of these hyphenated procedures for the analysis of fumonisins are their selectivity and sensitivity, and the fact that, in contrast with UV or fluorescence detection, there is no need for derivatization (pre- or post-column) (Zöllner and MayerHelm 2006).

The aim of this study was to apply reversed-phase high-performance liquid chromatography/electrospray ionization - ion trap and time-of-flight mass spectrometry (RP-HPLC/ESI-ITMS and RP-HPLC/ESI-TOFMS) to investigate and characterize six new, higher molecular weight FB analogues of fumonisins (three pairs of isomers with different $\mathrm{m} / \mathrm{z}$ values) extracted from a Fusarium verticillioides-infected solid rice culture. 
This is the first report on the detection of fumonisins in which, besides two TCA moieties, there is a third esterifying agent in the molecule.

\section{MATERIALS AND METHODS}

\section{Chemicals}

The $\mathrm{FB}_{1}$ standard and methanol $(\mathrm{MeOH}$, gradient grade) were purchased from SigmaAldrich Ltd. (Budapest, Hungary). Acetonitrile (MeCN, hypergrade) was from Merck Ltd (Budapest, Hungary). Purified water with a resistivity of $18 \mathrm{M} \Omega$ was delivered with a Nanopure II (Barnstead/Thermolyne Co., Dubuque, IA, USA) water purification device.

\section{Culturing of Fusarium verticillioides and extraction of fumonisins produced}

A Fusarium verticillioides isolate acquired from maize stalk (isolate no. Fv 16) was identified via its macro- and micromorphological characteristics and grown on a solid rice culture as described earlier (Bartók et al. 2006, 2010). It was demonstrated in those reports that this isolate has a good fumonisin-producing capability, yielding $18.27 \mathrm{mg} \mathrm{g}^{-1}$ $\mathrm{FB}_{1}$ toxin. The freeze-dried culture material containing fumonisins was extracted with a mixture of $\mathrm{MeOH} / \mathrm{H}_{2} \mathrm{O}(75 / 25$, v/v), using a high-speed homogenizer UltraTurrax T25 (IKA, Staufen, Germany) at $9500 \mathrm{rpm}$ for $4 \mathrm{~min}$. After extraction, and centrifugation (10000xg for $10 \mathrm{~min})$, the supernatant was filtered through a PTFE membrane $(0.2 \mu \mathrm{m})$ into an HPLC autosampler vial and was subsequently analysed with the instruments detailed below.

\section{RP-HPLC/ESI-ITMS and RP-HPLC/ESI-TOFMS analyses of fumonisins}

The instrumental parameters were described in detail recently (Bartók et al. 2010). Briefly, the fumonisins extracted from the solid rice culture material were analysed by http://mc.manuscriptcentral.com/tfac Email: fac@tandf.co.uk 
RP-HPLC/ESI-ITMS and also RP-HPLC/ESI-TOFMS at two research locations, where different Agilent (Santa Clara, CA, USA) HPLC systems (1090 Series II with DR5 binary pump and 1200 Series with binary pump) were attached to the mass spectrometers. Since the dead volume of the flow path of the 1200 Series HPLC system applied is higher than that of the 1090 Series II HPLC, the pulse damper from the 1200 Series pump was removed in order to decrease the retention time differences for the fumonisins on the two HPLC systems. A YMC-Pack J'sphere ODS H80 (YMC Europe GmbH, Dinslaken, Germany) (250 mm x $2.1 \mathrm{~mm}, 4 \mu \mathrm{m})$ HPLC column and a flat (24\% B to $40 \% \mathrm{~B}$ in 79 min, then increased to $100 \% \mathrm{~B}$ in $15 \mathrm{~min}$ ) linear binary gradient of $\mathrm{H}_{2} \mathrm{O}(\mathrm{A})$ and $\mathrm{MeCN}$ (B) (each supplemented with $0.1 \%(\mathrm{v} / \mathrm{v})$ formic acid) were applied at a flow rate of 0.2 $\mathrm{ml} \min ^{-1}$ for the separation of the compounds. Mass spectrometric detection was performed with a Varian (Palo Alto, CA, USA) 500MS IT, and on Agilent 6210 TOF mass spectrometers. Both mass spectrometers were equipped with ESI ion sources and operated in positive ion mode. Relative quantitation ( $\%$ of $\left.\mathrm{FB}_{1}\right)$ of the new compounds was performed by ESI-ITMS, using an external standard (ESTD) method in a 5 order of magnitude concentration range of an $\mathrm{FB}_{1}$ calibration standard dissolved in $\mathrm{MeCN} / \mathrm{H}_{2} \mathrm{O}$ $50 / 50(\mathrm{v} / \mathrm{v})$. The quantitative evaluation of the new compounds by using ESTD calibration of $\mathrm{FB}_{1}$ provided only approximate data, because the polarities of the detected new fumonisins are very different from that of $\mathrm{FB}_{1}$; naturally, the ionization of the new compounds is assumed, but is not known to be the same as that for $\mathrm{FB}_{1}$.

\section{RESULTS AND DISCUSSION}

Thanks to their outstanding sensitivity in full scan mode, mass spectrometers equipped with IT mass analysers are eminently suitable for the detection and partial identification of new secondary metabolites (e.g. mycotoxins) and their isomers (Josephs 1996; Bartók 
et al. 2006, 2008, 2010). As illustrated by the $\mathrm{MS}^{2}$ spectrum of $\mathrm{FB}_{1}$ toxin (Fig. 2), the product ion spectra of the molecular ions $\left([\mathrm{M}+\mathrm{H}]^{+}\right)$of fumonisins are highly characteristic; in other words, it is easy to decide almost at a glance whether or not a given product ion spectrum is produced by a fumonisin. In most fumonisins, the backbone is esterified by two organic acid molecules (most often TCA), and accordingly the product ion spectra contain three groups of fragment ions (indicated by 1, 2 and 3 in Fig. 2). The first group of fragment ions consists of the dehydrated molecular ions, the second is the $[\mathrm{M}+\mathrm{H}-\mathrm{TCA}]^{+}$group and the third is the $[\mathrm{M}+\mathrm{H}-2 \mathrm{TCA}]^{+}$group. It is characteristic of the product ion spectra of the fumonisins that, within a given product ion group, there is a difference of $18 \mathrm{Da}$ between the masses of the neighboring ions, corresponding to the splitting-off of one $\mathrm{H}_{2} \mathrm{O}$ molecule from the larger molecular or fragment ion. The difference between the $\mathrm{m} / \mathrm{z}$ values of the corresponding ions of the neighboring product ion groups yields the molar mass of the organic acid esterifying the backbone (TCA or, in the case of a few minor fumonisins, cis-aconitic acid, oxalfumaric acid or oxalsuccinic acid) (Bartók et al. 2006, 2008). In the course of our earlier HPLC/ESI-ITMS studies these characteristics indicated that isolates of Fusarium verticilliodes produce as yet unpublished fumonisins of higher molecular mass. Under the given experimental conditions, these fumonisins were eluted from the HPLC column at close to $100 \% \mathrm{MeCN}$, demonstrating that these components are considerably more apolar than other fumonisins so far described. The $\mathrm{m} / \mathrm{z}$ values of the fragment ions in the $\mathrm{MS}^{2}$ spectra, including the hydrocarbon backbone at $\mathrm{m} / \mathrm{z}, 299$, revealed that the structures of these new fumonisins are highly similar to that of $\mathrm{FB}_{1}$ toxin, except for the presence of additional functional groups. We assumed that the new substituents might be carboxylic acids esterifying the free $\mathrm{OH}$ groups of the fumonisin backbone, carboxylic acids that had not been identified on the fumonisin backbone. We were earlier unable to identify these 
fumonisins with our ITMS (lack of exact mass measurement). However, component identification following RP-HPLC separation was achieved by using an ESI-MS instrument equipped with a TOF mass analyser suitable for exact mass measurement. Three research groups had previously mentioned application of the TOFMS technique in fumonisin research, but neither of them utilized the procedure for the analysis of fumonisin isomers (Lemke et al. 2001; Senyuva and Gilbert 2008; Mogensen et al. 2010). We recently verified the usefulness of exact mass measurement by TOFMS during the identification of new $\mathrm{FB}_{1}$ isomers (Bartók et al. 2010). Since the HPLC equipment used in these TOFMS measurements was different from that used in earlier ITMS analyses, slightly different retention times were obtained for the same components. As shown in Tables 1 and 2, however, the retention times (relative to $\mathrm{FB}_{1}$ toxin) of the same components separated in the two different HPLC systems were highly similar. The differences between the retention times relative to $\mathrm{FB}_{1}$ lay in the range $0.085-0.088$. After full scan analysis by RP-HPLC/ESI-TOFMS, the data-processing software (Mass Hunter) of the equipment was asked to produce both the total ion and the extracted ion chromatograms (EICs) at $m / z$ values of 960, 984 and 986 (Fig. 3). Nevertheless, similarly to RP-HPLC/ESI-ITMS, the total ion chromatogram obtained by RP-HPLC/ESITOFMS did not display these minor components in addition to the main components $\left(\mathrm{FB}_{1}, \mathrm{FB}_{2}, \mathrm{FB}_{3}\right.$ and $\mathrm{FB}_{4}$ ). TOFMS EICs (Fig. 3) and ITMS EICs (chromatogram not shown), however, unambiguously indicated six new fumonisins in the retention time range 90.623-91.928 $\mathrm{min}$ and $89.324-90.569 \mathrm{~min}$, respectively, i.e. two components at each of three different $\mathrm{m} / \mathrm{z}$ values. The leading suggestions of the Mass Hunter software for all six fumonisins were the following empirical formulae (unprotonated) and the corresponding exact mass values $\left([\mathrm{M}+\mathrm{H}]^{+}\right): \mathrm{C}_{50} \mathrm{H}_{89} \mathrm{NO}_{16} \quad(960.62541) ; \mathrm{C}_{52} \mathrm{H}_{89} \mathrm{NO}_{16}$ (984.62541) and $\mathrm{C}_{52} \mathrm{H}_{91} \mathrm{NO}_{16}$ (986.64106). Subtraction of the empirical formula of $\mathrm{FB}_{1}$ 
toxin $\left(\mathrm{C}_{34} \mathrm{H}_{59} \mathrm{NO}_{15}\right)$ from these empirical formulae, followed by addition of the $\mathrm{H}_{2} \mathrm{O}$ removed from a $\mathrm{OH}$ group of the fumonisin backbone and the organic acid molecules in the course of esterification, yielded the empirical formulae of the organic (fatty) acids esterifying the third $\mathrm{OH}$ group of the backbone of the $\mathrm{FB}_{1}$ toxin, i.e. $\mathrm{C}_{16} \mathrm{H}_{32} \mathrm{O}_{2}$ (palmitic acid, PA), $\mathrm{C}_{18} \mathrm{H}_{32} \mathrm{O}_{2}$ (linoleic acid, LA) and $\mathrm{C}_{18} \mathrm{H}_{34} \mathrm{O}_{2}$ (oleic acid, OA). With regard to the currently accepted nomenclature $\left(\mathrm{FB}_{1}, \mathrm{PHFB}_{1}\right.$ (partially hydrolysed $\mathrm{FB}_{1}$ ) and $\mathrm{HFB}_{1}$ (fully hydrolysed $\left.\mathrm{FB}_{1}\right)$ ), the new fumonisins were named esterified $\mathrm{FB}_{1}\left(\mathrm{EFB}_{1}\right)$ toxins. The abbreviation at the end of the name (PA, LA or OA) indicates the organic acid, esterifying the third $\mathrm{OH}$ group of the fumonisin backbone. Thus, the suggested names of the six new identified fumonisins are $\mathrm{EFB}_{1} \mathrm{PA}$, iso- $\mathrm{EFB}_{1} \mathrm{PA}, \mathrm{EFB}_{1} \mathrm{LA}$, iso-EFB $\mathrm{LA}_{1}$, $\mathrm{EFB}_{1} \mathrm{OA}$ and iso-EFB $\mathrm{OA}_{1} \mathrm{O}$. The mass accuracy (based on the measured and the calculated mass values) of the new $\mathrm{EFB}_{1}$ toxins was in the range between 0.1 and -1.1 ppm. Data relating to the RP-HPLC/ESI-TOFMS measurements are listed in Table 1.

Our TOFMS measurements confirmed that the signals of the new fragment ion groups (4, 5 and 6$)$ in the $\mathrm{MS}^{2}$ spectra obtained by ITMS are due to the presence of the third organic acid on the fumonisin backbone (Fig. 4). The experimental data obtained by ITMS allow conclusions that complement the fragmentation pathways published earlier (Bartók et al. 2006, 2010). Figure 5a-c depicts theoretically possible pathways for the fragmentation of the newly detected fumonisins. Of these theoretically possible reaction pathways, dominant routes can be suggested by comparison of the $m / z$ values of the $\mathrm{MS}^{2}$ spectra shown in Figs 4 and 5a-c. No experiments were performed to address fragmentations depending on the CID energy, and it is therefore not possible to distinguish the roles of kinetic and thermodynamic parameters at this point. It is currently assumed that, the main fragmentation pathways can be characterized by the abundances of the ions in the product ion spectra. The experimental data mentioned above draw 
attention to various features regarding the dominant fragmentation pathways. Firstly, it is immediately apparent that the fragmentation patterns (abundance systems) of the $\mathrm{MS}^{2}$ spectra of the molecular ions of the newly detected fumonisins differ markedly from those of previously published fumonisins (Fig. 4): for the new fumonisins, there are six groups of fragment ions instead of the three characteristic of the $\mathrm{MS}^{2}$ spectra of the molecular ions $\left([\mathrm{M}+\mathrm{H}]^{+}\right)$of most fumonisins (Figs 2 and 4). Secondly, from the six groups of fragment ions, the ions $(\mathrm{m} / \mathrm{z}$ values) of groups 4,5 and 6 are also present in the groups of fragment ions of the mass spectra of the $\mathrm{FB}_{1}$ toxin and its isomers (1-3 in Fig. 2) (Bartók et al. 2010). The explanation seems obvious: in the MS fragmentation of $\mathrm{EFB}_{1}$-type fumonisins, the fatty acid or its ketene form is split off the molecule before either of the TCAs, and two of the ions characteristic of the $\mathrm{MS}^{2}$ spectrum of $\mathrm{FB}_{1}$ toxin, i.e. the ions at $m / z 704$ and $m / z$ 722, are produced. From this step on, the theoretical MS fragmentation scheme of the $\mathrm{EFB}_{1}$ components is identical with that of $\mathrm{FB}_{1}$ toxin. Thirdly, it is of diagnostic value that the $\mathrm{m} / \mathrm{z}$ values of the hydrocarbon backbones detected at the end of the fragmentation in the $\mathrm{MS}^{2}$ spectra of the molecular ions of the newly detected fumonisins (299 Da) are identical with the $\mathrm{m} / z$ value of the hydrocarbon backbone in the mass spectra of $\mathrm{FB}_{1}$ toxin and its isomers. From the predominant directions of fragmentation, the example of a fragmentation previously unknown among fumonisins is shown in Fig. 6 for $\mathrm{EFB}_{1} \mathrm{LA}(\mathrm{C}-10$ is the presumed esterification site for the LA). The fragmentation patterns are similar for the other $\mathrm{EFB}_{1} \mathrm{~s}$ and for the iso- $\mathrm{EFB}_{1}$ components. It follows from the structures of the new esterified fumonisins that groups modifying the backbone are split off in the course of fragmentation, i.e. C-O and C-N bond scission leads to the elimination of $\mathrm{H}_{2} \mathrm{O}$, organic acids (TCA, LA, OA or PA) and $\mathrm{NH}_{3}$. From the product ions formed as a result of fragmentation, it is clear that TCA can also be eliminated in a stepwise manner, while $\mathrm{H}_{2} \mathrm{O}$ is released with the concomitant http://mc.manuscriptcentral.com/tfac Email: fac@tandf.co.uk 
formation of the corresponding anhydride (TCAD 158 Da, Fig. 7). The splitting-off of TCA and the new fatty acids (LA, OA or PA) esterifying the backbone in the form of their ketene (TCAK 158 Da, LAK 262 Da, OAK 264 Da and PAK 238 Da, Fig. 7) was also observed, as can be seen in the theoretical fragmentation pathways (Fig. 5a-c) and the $M S^{2}$ spectra (Fig. 4). The $\mathrm{MS}^{2}$ spectra permit, the following general observations: (i) the ions produced by the fragmentation of LA, OA or PA were most abundant; (ii) the product ions with the lowest abundance were those formed by the splitting-off of 2TCA; (iii) the sequence of the groups of fragment ions according to abundances is $4>2>5>6 \geq 1>3$ for $\mathrm{EFB}_{1}$ and $4>5>6>1 \geq 2>3$ for iso-EFB ${ }_{1}$. The characteristic data (retention time, retention time relative to $\mathrm{FB}_{1}$, quantity relative to $\mathrm{FB}_{1}$ and $\mathrm{MS}^{2}$ spectral information on the molecular ions) for the $\mathrm{EFB}_{1}$ compounds, obtained by RP-HPLC/ESIITMS, are detailed in Table 2 . The relative quantities $\left(\%\right.$ of $\left.\mathrm{FB}_{1}\right)$ of the new fumonisins were in the range $0.003-0.036 \%$. Their total amount was $0.1 \%$ of the $\mathrm{FB}_{1}$ concentration, which may be rated as significant when it is considered that these new components are much more apolar than earlier-described fumonisins, and their uptake into and toxicity elicited in the various tissues of living organisms may therefore also be significantly different from those of other fumonisins.

The experimental results presented in this article clearly revealed that the parallel use of two hyphenated techniques (RP-HPLC/ESI-ITMS and RP-HPLC/ESI-TOFMS) was essential for identification of new type of fumonisins with three acyl groups, i.e. there are situations when a single hyphenated technique is not sufficient for the identification of a new compound. Of course, neither procedure could determine the relative and absolute configurations of the new fumonisins. In order to elucidate the structures of these toxins, other spectroscopic techniques, such as NMR, XRD and ORD, must be used. However, 
to perform these structural examinations and to examine the toxicity of these compounds, the most abundant $\mathrm{EFB}_{1}$ isomers should first be isolated.

\section{Acknowledgements}

Financial support was provided by EC (KBBE-2007-22269-2 MYCORED) and Hungarian State Research (OTKA 77612) grants.

\section{References}

Bartók T, Szécsi Á, Szekeres A, Mesterházy Á, Bartók M. 2006. Detection of new fumonisin mycotoxins and fumonisin-like compounds by reversed-phase highperformance liquid chromatography/electrospray ionization ion trap mass spectrometry. Rapid Commun Mass Spec. 20:2447-2462.

Bartók T, Szekeres A, Szécsi Á, Bartók M, Mesterházy Á. 2008. A new type of fumonisin series appeared on the scene of food and feed safety. Cereal Res Commun Suppl B. 36:315-319.

Bartók T, Tölgyesi L, Szekeres A, Varga M, Bartha R, Szécsi Á, Bartók M, Mesterházy Á. 2010. Detection and characterization of twenty-eight isomers of fumonisin B1 (FB1) mycotoxin in a solid rice culture infected with Fusarium verticillioides by reversed-phase high-performance liquid chromatography/electrospray ionization timeof-flight and ion trap mass spectrometry. Rapid Commun Mass Spec. 24:35-42.

Bezuidenhout SC, Gelderblom WCA, Gorst-Allam CP, Horak RM, Marasas WFO, Spiteller G, Vleggaar R. 1988. Structure elucidation of the fumonisins, mycotoxins from Fusarium moniliforme. J Chem Soc-Chem Commun. 743-745.

Bolger M, Coker RD, DiNovi M, Gaylor D, Gelderblom WCA, Olsen M. in: Safety evaluation of certain mycotoxins in food, Edited by the Fifty-sixth meeting of the Joint 
FAO/WHO Expert Committee on Food Additives (JECFA). FAO, Rome. 2001, pp. 103-280.

Colvin BM, Harrison LR. 1992. Fumonisin-induced pulmonary-edema and hydrothorax in swine. Mycopathologia 117:79-82.

Doko MB, Rapior S, Visconti A, Schjoth JE. 1995. Incidence and levels of fumonisin contamination in maize genotypes grown in Europe and Africa. J Agr Food Chem. 43:429-434.

Fazekas B, Bajmócy E, Glávits R, Fenyvesi A, Tanyi J. 1998. Fumonisin B-1 contamination of maize and experimental acute fumonisin toxicosis in pigs. J Vet Med B. $45: 171-181$.

Frisvad JC, Smedsgaard J, Samson RA, Larsen TO, Thrane U. 2007. Fumonisin B-2 production by Aspergillus niger. J Agr Food Chem. 55:9727-9732.

Gelderblom WCA, Kriek NPJ, Marasas WFO, Thiel PG. 1991. Toxicity and carcinogenicity of the Fusarium moniliforme metabolite, fumonisin-B1, in rats. Carcinogenesis 12:1247-1251.

IARC, International Agency for Research on Cancer, Fumonisin B1. IARC Monograps on the Evaluation of Carcinogenic Risks to Humans, Some Traditional Medicines, Some Mycotoxins, Naphtalene and Styrene; IARC: Lyon, France. 2002, 82, pp. 301366.

Josephs JL. 1996. Detection and characterization of fumonisin mycotoxins by liquid chromatography electrospray ionization using ion trap and triple quadrupole mass spectrometry. Rapid Commun Mass Spec. 10:1333-1344.

Kellerman TS, Marasas WFO, Thiel PG, Gelderblom WCA, Cawood M, Coetzer JAW. 1990 Leukoencephalomalacia in 2 horses induced by oral dosing of fumonisin-B1. Onderstepoort J Vet Res. 57:269-275. 
Ledoux DR, Brown TP, Weibking TS, Rottighaus GE. 1992. Fumonisin toxicity in broiler chicks. J Vet Diag Invest. 4:330-333.

Lemke SL, Ottinger SE, Ake CL, Mayura K, Phillips TD. 2001. Deamination of fumonisin B-1 and biological assessment of reaction product toxicity. Chem Res Toxicol. 14:11-15.

Logrieco A, Ferracane R, Haidukowsky M, Cozzi G, Visconti A, Ritieni A. 2009. Fumonisin B2 production by Aspergillus niger from grapes and natural occurrence in must. Food Addit Contam. 26:1495-15.

Mogensen JM, Frisvad JC, Thrane U, Nielsen KF. 2010. Production of fumonisin B2 and B4 by Aspergillus niger on grapes and raisins. J Agr Food Chem. 58:954-958.

Musser SM, Gay ML, Mazzola EP. 1996. Identification of a new series of fumonisins containing 3-hydroxypyridine. J Nat Prod. 59: 970-972.

Noonim P, Mahakarnchanakul W, Nielsen KF, Frisvad JC, Samson RA. 2009. Fumonisin B2 production by Aspergillus niger in Thai coffee beans. Food Addit Contam. 26:94100.

Rheeder JP, Marasas WFO, Thiel PG, Sydenham EW, Shephard GS, Van Schalkwyk DJ. 1992. Fusarium moniliforme and fumonisins in corn in relation to human esophageal cancer in Transkei. Phytopathology 82:353-357.

Rheeder JP, Marasas WFO, Vismer HF. 2002. Production of fumonisin analogs by Fusarium species. Appl Environ Microbiol. 68:2101-2105.

Riley RT, Hinton DM, Chamberlain WJ, Bacon CW, Wang E, Merrill AH, Voss KA. 1994 Dietary fumonisin B-1 induces disruption of sphingolipid metabolism in sparguedawley rats - a new mechanism of nephrotoxicity. J Nutr. 124:594-603.

Seifert KA, Aoki T, Baayen RP, Brayford D, Burgess LW, Chulzes S, Gams W, Geiser D, deGruyter J, Leslie JF, Logrieco A, Marasas WFO, Nirenberg HI, Odonnell K, http://mc.manuscriptcentral.com/tfac Email: fac@tandf.co.uk 
Rheeder JP, Samuels GJ, Summerell BA, Thrane U, Waalijk C. 2003. The name Fusarium moniliforme should no longer be used. Mycol Res. 107:643-644.

Senyuva HZ, Gilbert J. 2008. Identification of fumonisin B-2, HT-2 toxin, patulin and zearalenone in dried figs by liquid chromatography-time-of-flight mass spectrometry and liquid chromatography-mass spectrometry. J Food Protect. 71:1500-1504.

Shephard GS, Thiel G, Stockenström S, Sydenham EW. 1996. Worldwide survey of fumonisin contamination of corn and corn-based products. J AOAC Int. 79:671-687.

Shephard GS, Marasas WFO, Leggott NL, Yazdanpanah H, Rahimian H, Safavi N. 2000. Natural occurrence of fumonisins in corn from Iran. J Agr Food Chem. 48:1860-1864.

Stack ME. 1998. Analysis of fumonisin B-1 and its hydrolysis product in tortillas. J AOAC Int. 81:737-740.

Ueno Y, Lijima K, Wang SD, Sugiura Y, Sekijima M, Tanaka T, Chen C, Yu SZ. 1997. Fumonisins as a possible contributory risk factor for primary liver cancer. A 3-year study of corn harvested in Haimen, China, by HPLC and ELISA. Food Chem Toxicol. $35: 1143-1150$.

Weibking TS, Ledoux DR, Brown TP, Rottighaus GE. 1993. Fumonisin toxicity in turkey poults. J Vet Diag Invest. 5:75-83.

Yoshizawa T, Yamashita A, Lou Y. 1994. Fumonisin occurrence in corn from high-risk and low-risk areas for human esophageal cancer in China. Appl Environ Microbiol. 60:1626-1629.

Zomborszky-Kovács M, Kovács F, Horn P, Vetési F, Repa I, Tornyos G, Tóth Á. 2002. Investigations into the time- and dose-dependent effect of fumonisin B-1 in order to determine tolerable limit values in pigs. Livest Prod Sci. 76:251-256. 
Zöllner P, Mayer-Helm B. 2006. Trace mycotoxin analysis in complex biological and food matrices by liquid chromatography-atmospheric pressure ionization mass spectrometry. J Chromatogr A. 1136:123-169.

1

2

5

6

7

8

9

10

11

12

13

14

15

16

17

18

19

20

21

22

23

24

25

26

27

28

29

30

31

32

33

34

35

36

37

38

39

40

41

42

43

44

45

46

47

48

49

50

51

52

53

54

55

56

57

58

59

60 


1
2
3
4
5
6
7
8
9
10
11
12
13
14
15
16
17
18
19
20
21
22
23
24
25
26
27
28
29
30
31
32
33
34
35
36
37
38
39
40
41
42
43
40
45
49
50
50
51
53
55
50

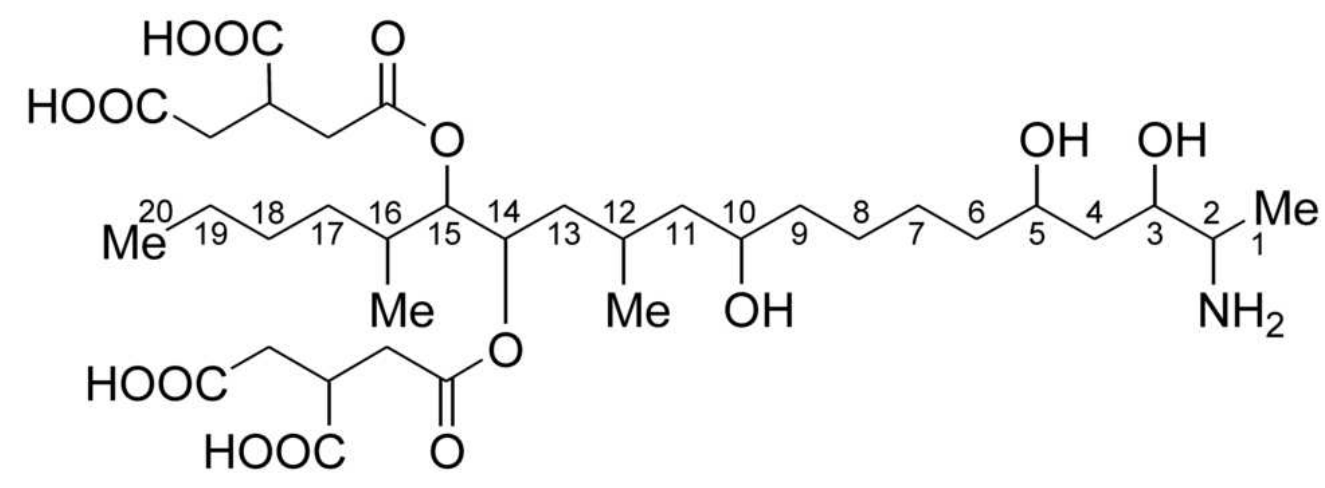

Figure 1. Structure of $\mathrm{FB}_{1}$ toxin. $41 \times 14 \mathrm{~mm}(600 \times 600 \mathrm{DPI})$ 


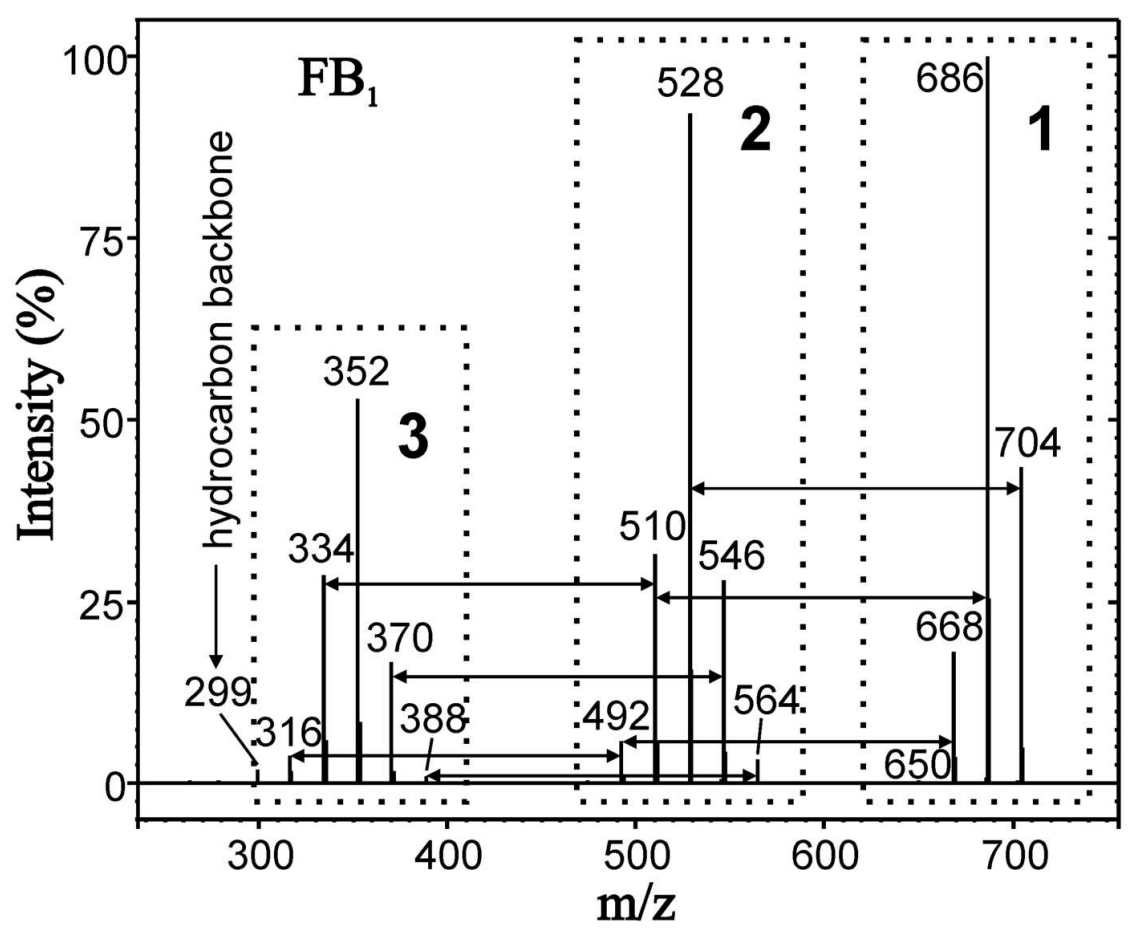

Figure 2. Product ion spectra (CID) of protonated molecules $\left([\mathrm{M}+\mathrm{H}]^{+}\right)$of $\mathrm{FB}_{1}$ with product ion groups (1-3) indicated. The left and right doubled arrows indicate the mass difference of $176 \mathrm{Da}$ (loss of one molecule of TCA) between the corresponding product ions of the neighbouring product ion groups.

$68 \times 53 \mathrm{~mm}(600 \times 600 \mathrm{DPI})$ 


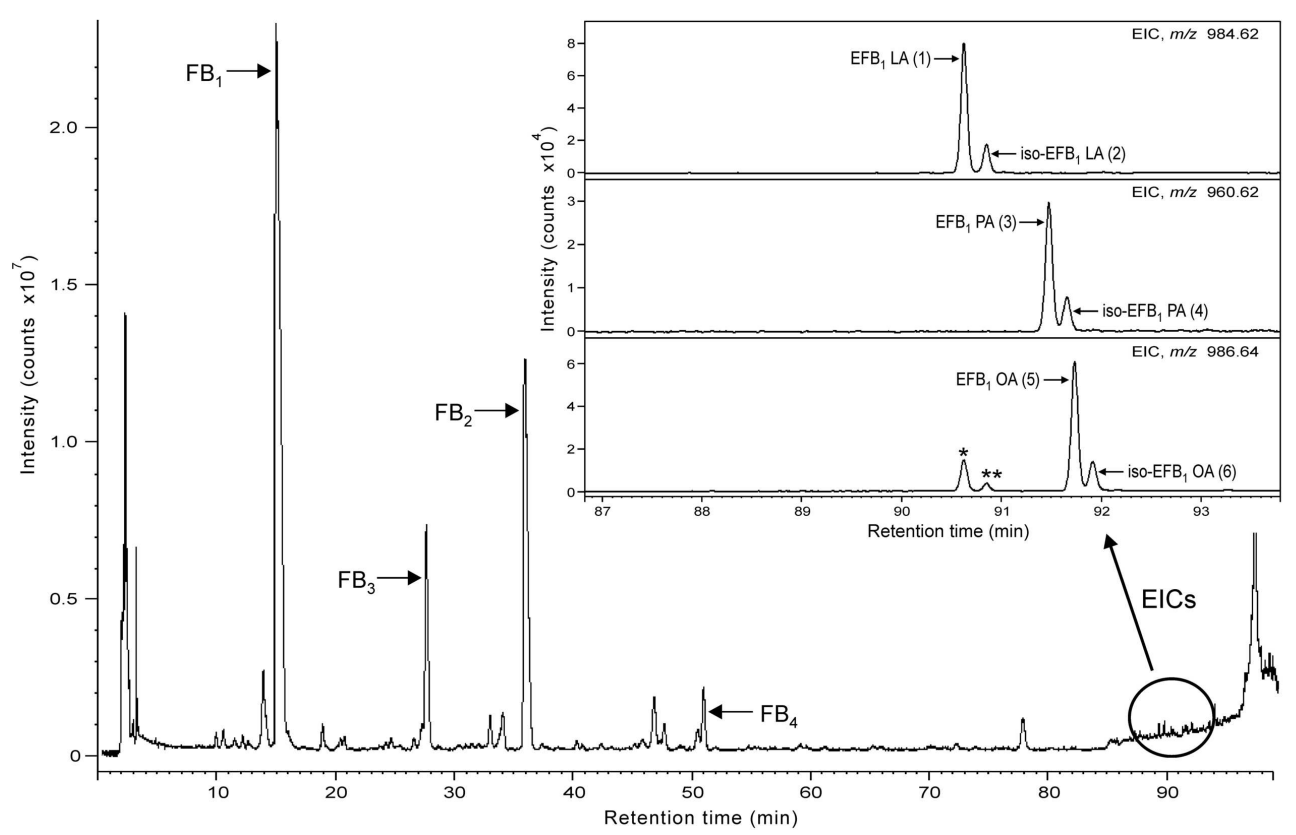

Figure 3. Total ion and extracted ion chromatograms (EICs, enlarged, at $m / z 984.62,960.62$ and 986.64) obtained by RP-HPLC/ESI-TOFMS on an extract of a solid rice culture infected with Fusarium verticillioides. The asterisks (* and **) indicate the isotope peaks of $\mathrm{EFB}_{1} \mathrm{LA}(1)$ and iso$\mathrm{EFB}_{1} \mathrm{LA}(2)$ at an $m / z$ value of 986.64 . $109 \times 74 \mathrm{~mm}(600 \times 600 \mathrm{DPI})$ 

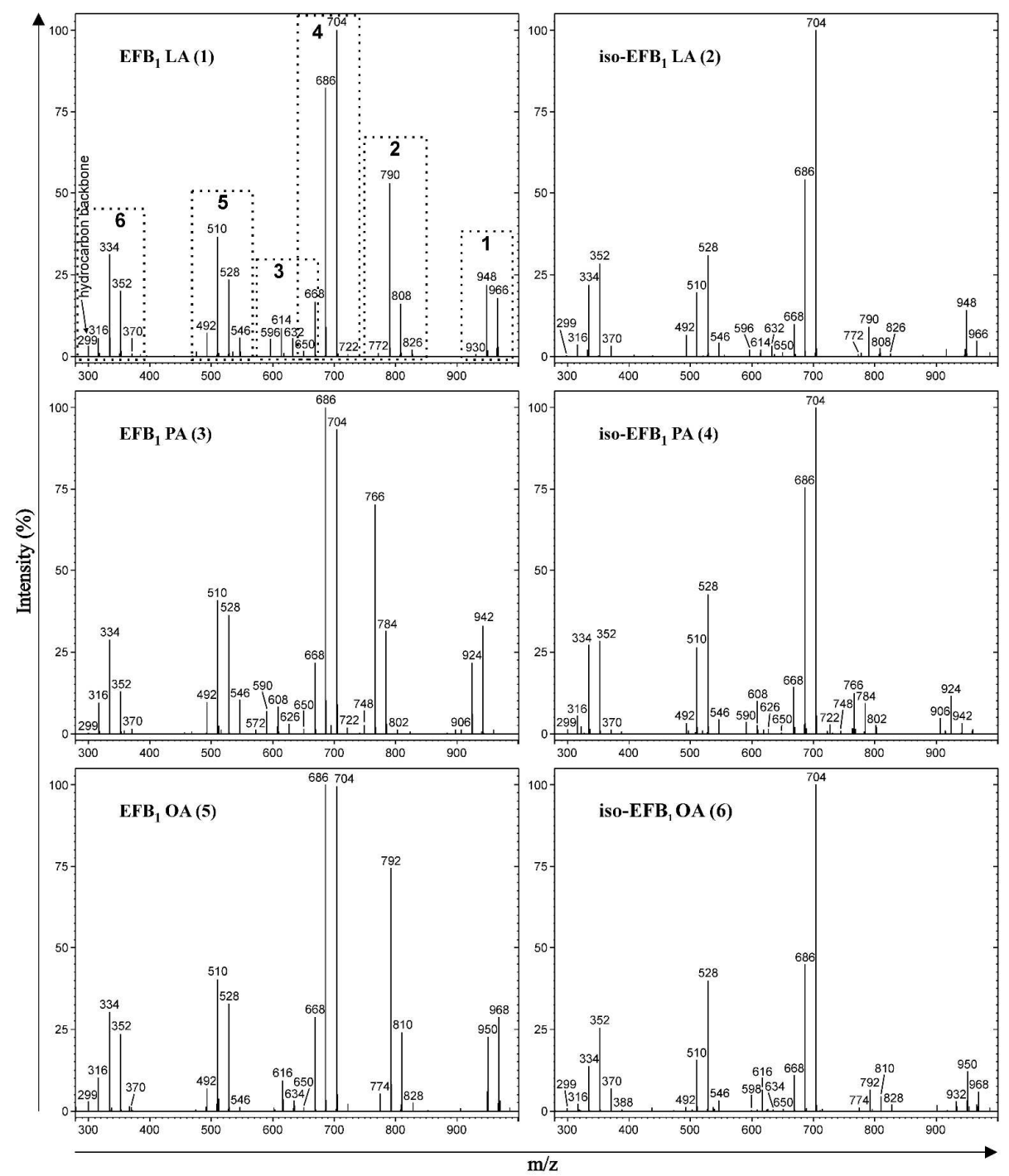

Figure 4. Product ion spectra (CID) of protonated molecules $\left([\mathrm{M}+\mathrm{H}]^{+}\right)$of esterified $\mathrm{FB}_{1}\left(\mathrm{EFB}_{1}\right)$ isomers: $\mathrm{EFB}_{1} \mathrm{LA}$ (1), iso- $\mathrm{EFB}_{1} \mathrm{LA}$ (2), $\mathrm{EFB}_{1} \mathrm{PA}$ (3), iso- $\mathrm{EFB}_{1} \mathrm{PA}$ (4), $\mathrm{EFB}_{1} \mathrm{OA}$ (5), iso- $\mathrm{EFB}_{1} \mathrm{OA}$ (6) by ESI-ITMS ${ }^{2}$. The product ion groups (1-6) are indicated in the $\mathrm{MS}^{2}$ spectrum of $[\mathrm{M}+\mathrm{H}]^{+}$at $\mathrm{m} / \mathrm{z} 984$ of $\mathrm{EFB}_{1} \mathrm{LA}(1)$.

$214 \times 243 \mathrm{~mm}(600 \times 600 \mathrm{DPI})$ 
Figure 5a-c. Theoretically possible fragmentation (CID) pattern characteristic only of protonated molecules $\left([\mathrm{M}+\mathrm{H}]^{+}\right)$of esterified $\mathrm{FB}_{1}\left(\mathrm{EFB}_{1}\right)$ isomers. (a) $\mathrm{EFB}_{1} \mathrm{LA}(1)$, iso-EFB $\mathrm{LA}_{1}$ (2); (b) EFB $\mathrm{FA}_{1} \mathrm{PA}$ (3), iso-EFB $\mathrm{EAA}_{1}$ (4); (c) $\mathrm{EFB}_{1} \mathrm{OA}(5)$, iso- $\mathrm{EFB}_{1} \mathrm{OA}(6)$. The vertical, horizontal and diagonal arrows indicate the loss of $\mathrm{H}_{2} \mathrm{O}$ (18 Da); TCAD or TCAK (158 Da), PAK (238 Da), LAK (262 Da), OAK (264

$\mathrm{Da})$ and TCA (176 Da), PA (256 Da), LA (280 Da), OA (282 Da) from the molecular and product ions, respectively. The $\mathrm{m} / \mathrm{z}$ values underlined were not observed in the mass spectra. See details in the text, and for abbreviations, see Fig. 7. $132 \times 216 \mathrm{~mm}(600 \times 600 \mathrm{DPI})$ 


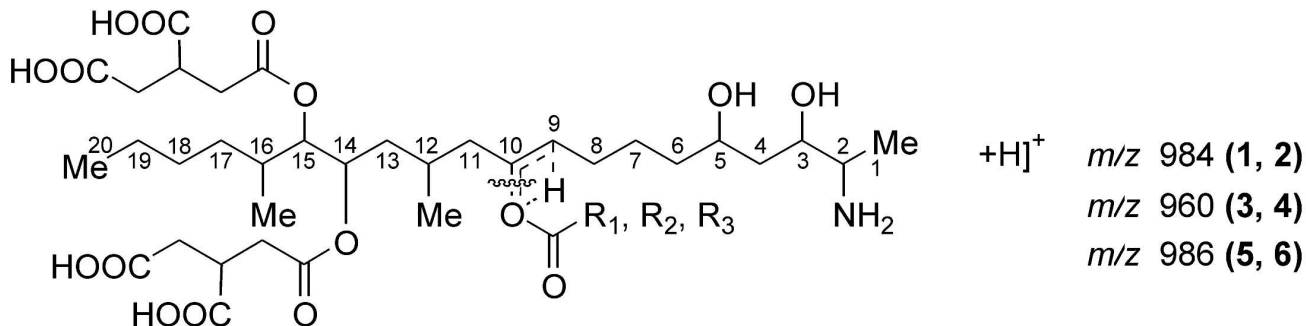

Figure 6. Assumed structures of some characteristic ions formed in the CID fragmentation processes of protonated molecules of $\mathrm{EFB}_{1}$ isomers. $\mathrm{C}-10$ is the presumed esterification site for the fatty acids. $185 \times 211 \mathrm{~mm}(600 \times 600 \mathrm{DPI})$ 
<smiles>O=C(O)CC1CC(=O)OC1=O</smiles>
tricarballylic anhydride (TCAD, $158 \mathrm{Da})$<smiles>O=CCC(C=O)C(=O)O</smiles>

ketene form of tricarballylic acid (TCAK, $158 \mathrm{Da})$

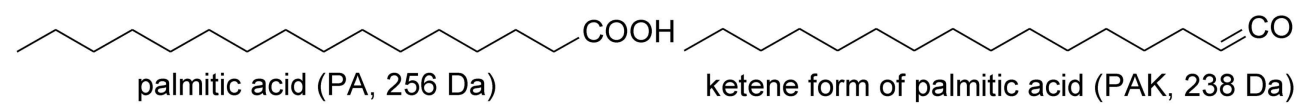

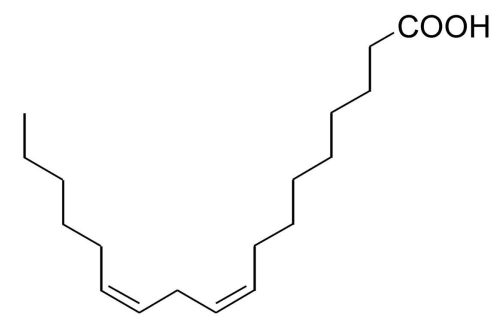

linoleic acid (LA, $280 \mathrm{Da})$

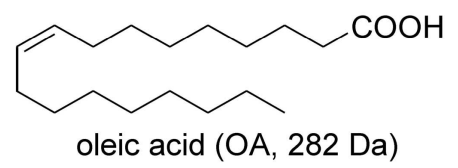

ketene form of palmitic acid (PAK, $238 \mathrm{Da}$ )

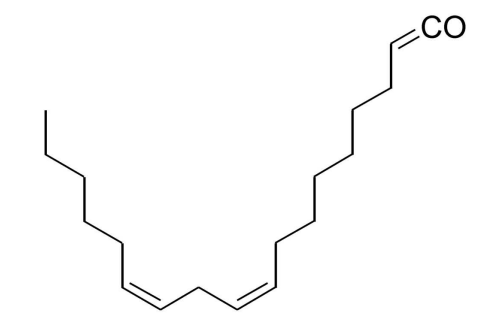

ketene form of linoleic acid (LAK, $262 \mathrm{Da})$

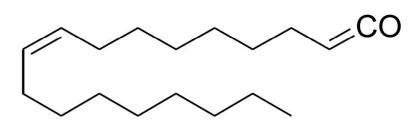

ketene form of oleic acid (OAK, $264 \mathrm{Da})$

Figure 7. Acids conjugated to the fumonisin backbone and structures of compounds possibly formed in the CID fragmentation processes of protonated molecules of $\mathrm{EFB}_{1}$ isomers. $128 \times 93 \mathrm{~mm}(600 \times 600 \mathrm{DPI})$ 
Table 1. Characteristic data obtained by RP-HPLC/ESI-TOFMS on new esterified $\mathrm{FB}_{1}\left(\mathrm{EFB}_{1}\right)$ isomers. 
Table 2. Characteristic data obtained by RP-HPLC/ESI-ITMS on new esterified $\mathrm{FB}_{1}\left(\mathrm{EFB}_{1}\right)$ isomers (for abbreviations, see Fig. 7).

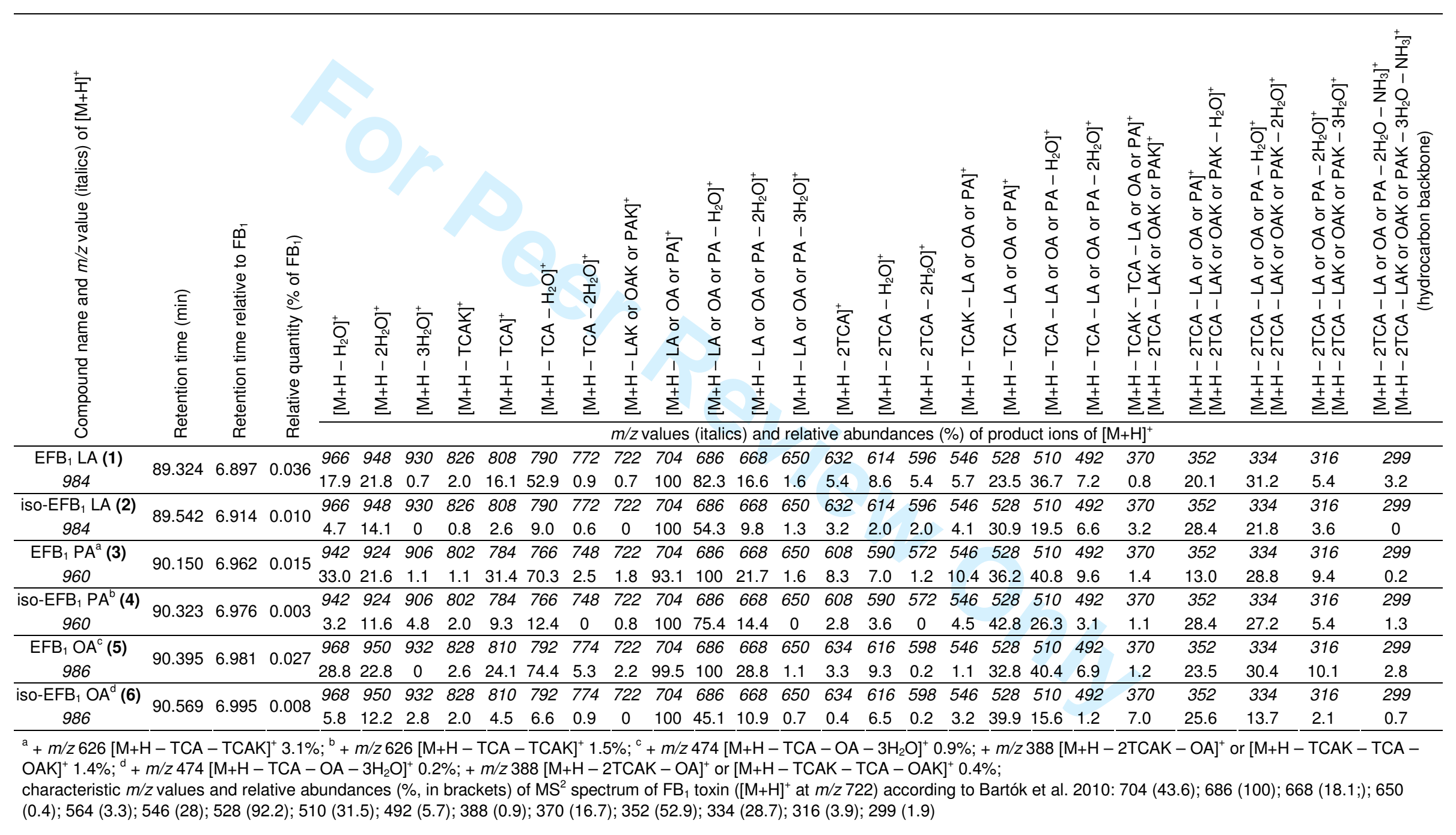

